\title{
Comparison of two- and three-dimensional sonography for the prediction of the extrathyroidal extension of papillary thyroid carcinomas
}

\author{
Yang Seon $\mathrm{Yi}^{1,}$, , Sang Soo Kim ${ }^{2,3},{ }^{*}$, Won Jin $\mathrm{Kim}^{2}$, Min Jung Bae ${ }^{4}$, Ji Hyun Kang ${ }^{4}$, Bo Gwang Choi ${ }^{4}$, \\ Yun Kyung Jeon ${ }^{2}$, Bo Hyun Kim², Byung Joo Lee ${ }^{5}$, Soo Geun Wang ${ }^{5}$, In Joo Kim²,3 and Yong Ki Kim
}

\begin{abstract}
${ }^{1}$ Department of Internal Medicine, Busan Veterans Hospital, Busan; ${ }^{2}$ Division of Endocrinology and Metabolism, Department of Internal Medicine, ${ }^{3}$ Biomedical Research Institute, Pusan National University Hospital, Busan; ${ }^{4}$ Department of Internal Medicine, Kim Yong Ki Internal Medicine Clinic, Busan; ${ }^{5}$ Department of Otorhinolaryngology-Head and Neck Surgery, Pusan National University Hospital, Busan, Korea
\end{abstract}

Received: November 26, 2014 Revised : March 24, 2015

Accepted: May 13, 2015

\section{Correspondence to}

In Joo Kim, M.D.

Division of Endocrinology and Metabolism, Department of Internal Medicine, Pusan National University Hospital, 179 Gudeokro, Seo-gu, Busan 49241, Korea

Tel: $+82-51-240-7224$

Fax: +82-51-254-3127

E-mail: injkim@pusan.ac.kr
Background/Aims: The purpose of this study was to compare the diagnostic validity of two-dimensional (2D) and three-dimensional (3D) ultrasonography (US) when predicting the extrathyroidal extension of papillary thyroid cancer.

Methods: All 2D data were interpreted in real time and 3D data were stored, rendered using tomographic ultrasound imaging (TUI), and then reviewed retrospectively.

Results: Extrathyroidal extension was present in 17 papillary thyroid cancers (24.3\%) on pathology reports. The presence of contact was significantly associated with extrathyroidal extension on both $2 \mathrm{D}$ and $3 \mathrm{D} \mathrm{US}(p=0.007$ and $p=0.003)$, and the sensitivity and specificity were not significantly different between $2 \mathrm{D}$ and ${ }_{3} \mathrm{D}$ US ( $p=1.000$ and $p=0.754)$. The coexistence of protrusion and contact was not significantly associated with extrathyroidal extension on either $2 \mathrm{D}$ or $3 \mathrm{D}$ sonogram.

Conclusions: Three-dimensional images rendered with TUI algorithms alone do not seem to be markedly superior to real-time 2D US in predicting the extrathyroidal extension of papillary thyroid cancer.

Keywords: Thyroid neoplasm; Tumor staging; Extrathyroidal extension; Three-dimensional ultrasonography; Tomographic ultrasound imaging

\footnotetext{
*These authors contributed equally to this work.
}

\section{INTRODUCTION}

Recently, there has been a marked increase in the incidence of small-sized thyroid cancer [1-3], and an accurate determination of the necessary extent of surgery has become a matter of concern. The presence of extrathyroidal extension changes the scope of surgery from thyroid lobectomy to a total or near-total thyroidectomy in the case of a unifocal papillary thyroid carcinoma that is 1 $\mathrm{cm}$ or smaller in size and clinically node-negative in a low-risk patient $[4,5]$. Additionally, papillary thyroid carcinomas, and most follicular cancers sized $4 \mathrm{~cm}$ or less that do not have evidence of cervical nodal metastases, may not require prophylactic central neck dissection in 
the absence of extrathyroidal extension [4,5].

Neck ultrasonography (US) has emerged as an essential preoperative staging modality for patients with a malignant thyroid nodule [4]. Several previous studies have evaluated the preoperative characteristics of US that may be predictive of the extrathyroidal extension of papillary thyroid cancer. These studies suggested the use of different criteria including the presence of contact itself [6] or various degrees of contact between the papillary thyroid cancer and the adjacent capsule $[7,8]$. A previous study conducted by our group revealed that contact with the capsule is predictive of extrathyroidal extension of papillary thyroid cancer and that contact in combination with protrusion into adjacent tissues is a stronger independent predictive factor [9].

Because conventional two-dimensional (2D) US has limitations regarding assessment in the coronal plane, some authors have proposed that evaluation with three-dimensional (3D) US is necessary [8,9]. During preoperative staging of endometrial cancer, cervical cancer, prostate cancer, and bladder cancer, ${ }_{3} \mathrm{D}$ US has been shown to be a useful tool for the detection of the invasion or extension of cancers into adjacent tissues [10-14]. However, to the best of our knowledge, only one recent study has evaluated the diagnostic performance of $3 \mathrm{D}$ US in the assessment of extrathyroidal extension of thyroid cancer [15].

This study aimed to compare the diagnostic accuracy of real-time $2 \mathrm{D}$ US data with that of static 3 D US data for the prediction of the extrathyroidal extension of papillary thyroid cancer into the adjacent capsule according to presence of contact and protrusion in an attempt to determine the usefulness of $3 \mathrm{D}$ US data rendered using tomographic ultrasound imaging (TUI).

\section{METHODS}

\section{Patients}

This study included 78 patients who underwent surgery for papillary thyroid cancer following diagnosis by fine needle aspiration between May 2011 and December 2011. In addition to undergoing routine $2 \mathrm{D}$ US preoperative staging, each patient was further evaluated using $3 \mathrm{D}$ US on the day prior to surgery. Following surgery, two patients were excluded because their final pathological results were not malignant (one patient had nodular hyperplasia with nuclear atypia, and the other had an adenomatous goiter with atypical follicular epithelial cells exhibiting oncocytic change), and five patients were excluded due to difficulty correctly matching their preoperative $3 \mathrm{D}$ US images with the nodule that was pathologically confirmed as thyroid cancer. Of the remaining 81 papillary thyroid carcinomas present in the remaining 71 patients, six carcinomas measuring more than $2 \mathrm{~cm}$ in pathological tumor size and five thyroid carcinomas with macrocalcification were also excluded due to difficulty in determining the presence of contact and/or protrusion. Thus, a total of 61 patients with 70 papillary thyroid cancers $2 \mathrm{~cm}$ or smaller in size constituted the final study population.

All patients underwent a total thyroidectomy with central compartment neck dissection; this is the surgical procedure of choice in our hospital. Additionally, selective lateral neck dissection was performed in five patients. The present study was approved by the Institutional Review Board of Pusan National University Hospital, and informed consent was obtained from all subjects.

\section{Preoperative ultrasound examinations and image assessment}

Both $2 \mathrm{D}$ and $3 \mathrm{D}$ images were obtained using one scanner (LOGIQ E9, GE Healthcare, Milwaukee, WI, USA) operated by three endocrinologists (authors JHK, BGC, and SSK) according to their duty schedule. The preoperative $2 \mathrm{D}$ US examination was performed using 3 to 11 $\mathrm{MHz}$ and 4 to $15 \mathrm{MHz}$ linear transducers, and the $3 \mathrm{D}$ US volume data was acquired using a 6 to $8 \mathrm{MHz}$ real-time four-dimensional linear transducer. The $3 \mathrm{D}$ volumes were scanned using automatic capture for the fine needle aspiration-proven thyroid papillary cancers and any additional suspicious malignant nodules.

The 2D US images were interpreted immediately following examination by the US operator for presence of contact with the thyroid capsule and presence of protrusion into adjacent structures. The $3 \mathrm{D}$ US data were stored and later rendered using the TUI method with a slice interval of 0.5 to $0.8 \mathrm{~mm}$ depending on the nodule size (Fig. 1). Two additional endocrinologists who had experience in thyroid US (authors YSY and SSK) and who were blind to the $2 \mathrm{D}$ US results reviewed the 


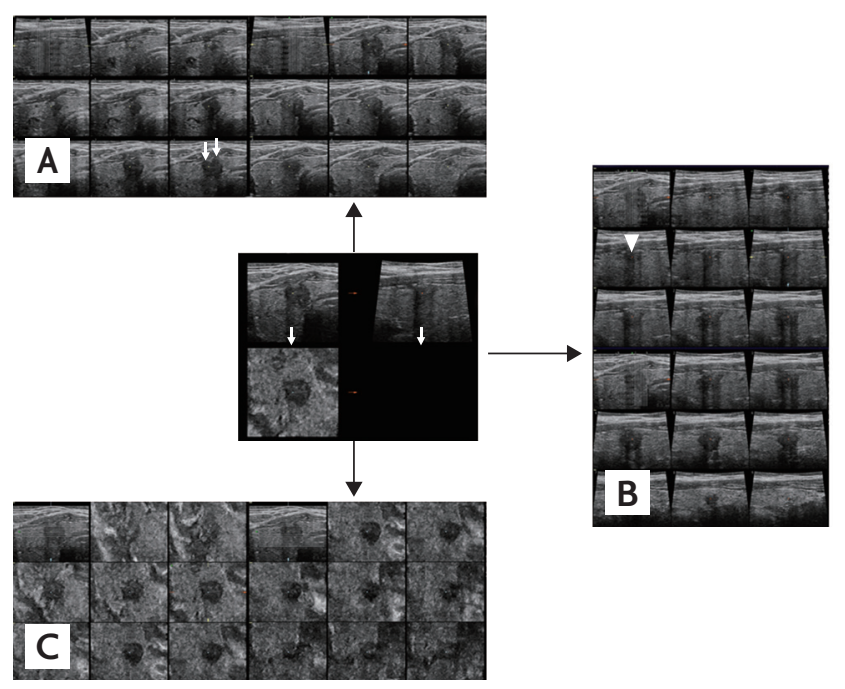

Figure 1. Three-dimensional ultrasonograms of a representative presence of both contact and protrusion ( $\left.\mathrm{C}_{1} \mathrm{P}_{1}\right)$ papillary thyroid carcinoma rendered using tomographic ultrasound imaging. A series of slices ( $0.5 \mathrm{~mm}$ apart) in the transverse plane (A), the longitudinal plane (B), and the coronal plane (C). The lesion shows contact and protrusion in the transverse (white arrows) and the longitudinal plane (arrowhead). After surgery, pathologic finding was negative for extrathyroidal extension.

TUI-rendered 3D US images to determine the contact and protrusion of the nodules. Both the $2 \mathrm{D}$ and ${ }_{3} \mathrm{D}$ data reviewers were blind to the pathological results.

Presence of contact was defined as the absence of grossly visible intervening normal thyroid tissue between the nodule and the adjacent thyroid capsule $[8,9]$. If a nodule exhibited contact, it was further assessed to determine whether it protruded into adjacent structures. The nodules were first categorized according to the presence of contact: absence of contact (Co) (Fig. 2) and presence of contact $(\mathrm{C} 1)$. And then $\mathrm{C} 1$ nodules were further categorized with regard to the presence of protrusion: presence of contact without protrusion (C1Po) (Fig. 3) and presence of protrusion in addition to contact (C1P1) (Fig. 4).

\section{Statistical analyses}

The presence of extrathyroidal extension was determined using the histopathological reports on the surgical specimens, and a two-sample $t$ test was performed to assess the association between the extrathyroidal extension and the size of the papillary thyroid carcinoma as measured by 2D US. Chi-square or Fisher exact
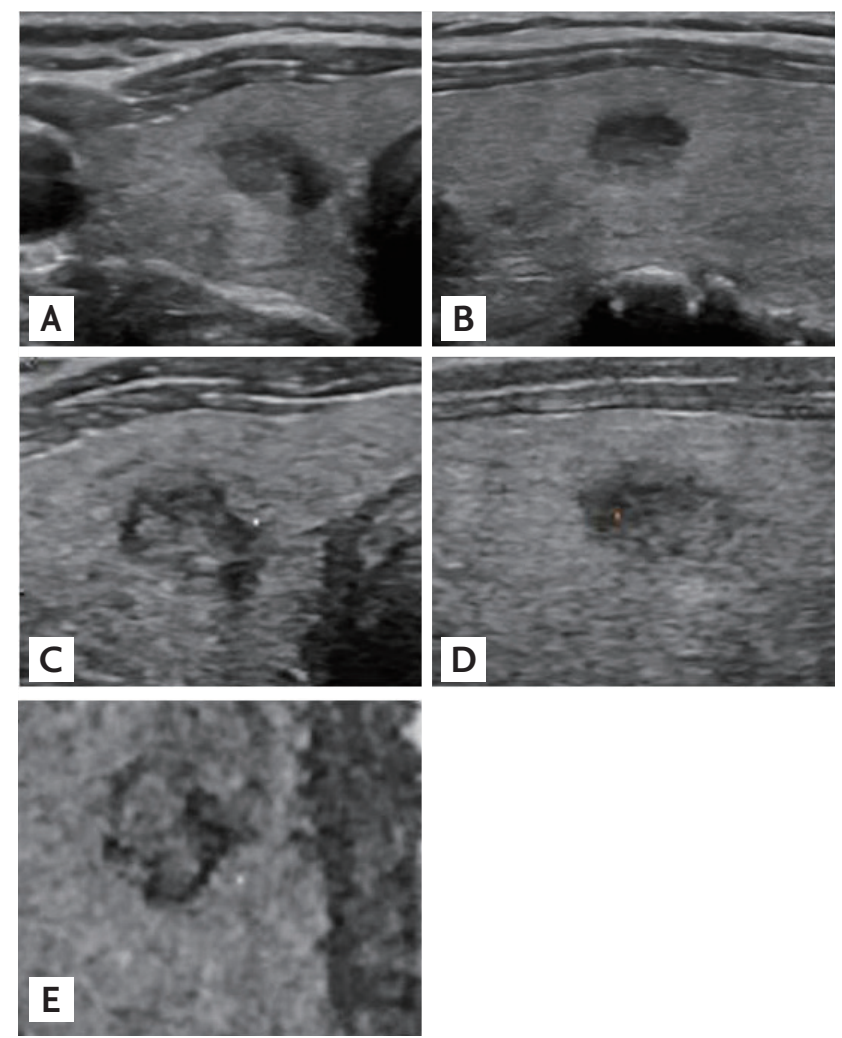

Figure 2. A representative absence of contact (Co) papillary thyroid carcinoma. Traverse (A) and longitudinal (B) sonograms from two-dimensional ultrasonography demonstrate the absence of contact by the papillary thyroid carcinoma. Tomographic ultrasound imaging rendered images of three-dimensional ultrasonography in the transverse (C), longitudinal (D), and coronal (E) planes are corresponding with the two-dimensional ultrasonographic findings. After surgery, pathologic report was also negative for extrathyroidal extension.

tests were used to assess the association between the US characteristics and the histopathological extrathyroidal extension. The sensitivity, specificity, positive predictive value, and negative predictive value of the US findings were calculated. Additionally, the odds ratio (OR) with 95\% confidence intervals (CIs) and the area under the curve (Az) for predicting extrathyroidal extension were analyzed for each of the US characteristics. To compare the sensitivity and specificity of $2 \mathrm{D}$ US with that of $3 \mathrm{D}$ US, a McNemar test was applied [16]. Subgroup analyses were performed following a diagnosis of micropapillary thyroid carcinoma ( $1 \mathrm{~cm}$ or smaller in size). All statistical analyses were conducted using SPSS version 18.0 (SPSS Inc., Chicago, IL, USA), and a p value of less than 0.05 was deemed to indicate statistical significance. 

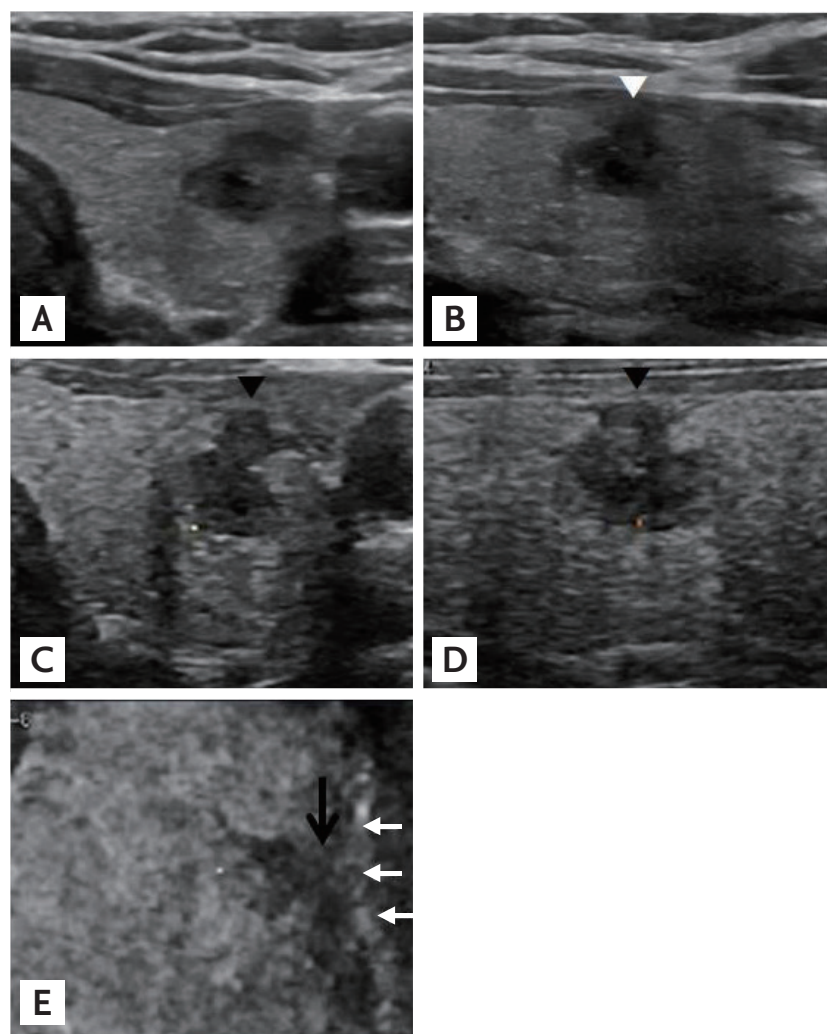

Figure 3. A representative presence of contact without protrusion $(\mathrm{C} 1 \mathrm{Po})$ papillary thyroid carcinoma. Transverse (A) and longitudinal (B) sonograms from two-dimensional ultrasonography demonstrating that the carcinoma is in contact with the thyroid capsule but does not protrude into adjacent structures (white arrowhead). Tomographic ultrasound imaging rendered images of three-dimensional ultrasonography in the transverse (C), longitudinal (D), and coronal (E) planes show that the papillary carcinoma is in contact with the capsule in the transverse and longitudinal planes (black arrowheads) without definite protrusion. In the coronal plane, the lesion is also considered in contact (black arrow) with the adjacent capsule (white arrows). Pathologic extrathyroidal extension was confirmed.

\section{RESULTS}

The demographic and clinicopathological characteristics of the 61 patients included in this study are presented (Table 1). The mean age was $48.7 \pm 13.1$ years (range, 17 to 75$)$. Of these, 19 patients (31.1\%) were younger than 45 years of age, 20 (32.8\%) had two or more papillary thyroid carcinomas, and 25 (41\%) had lymph node metastasis; none of the patients had distant metastasis at the time of diagnosis of thyroid cancer. The mean interval between preoperative $2 \mathrm{D}$ and $3 \mathrm{D}$ US was 6.7 days (range, o to 83 ). The preoperative $2 \mathrm{D}$ US characteristics of the
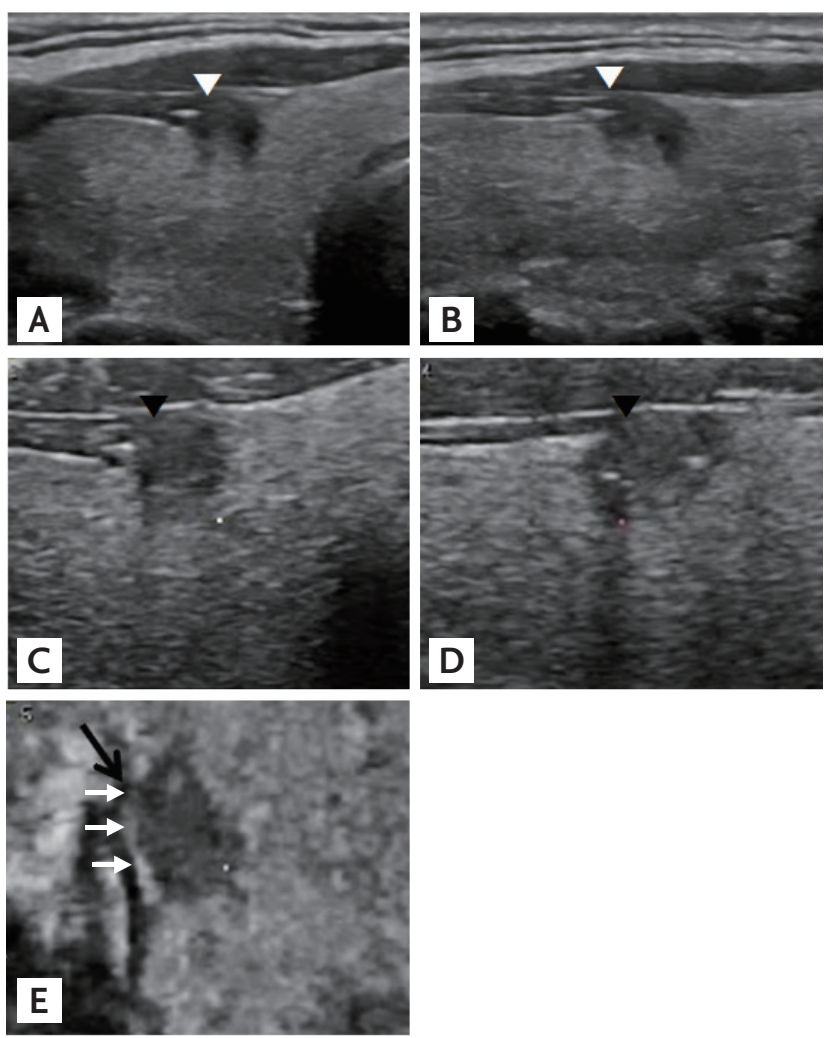

Figure 4. A representative presence of both contact and protrusion $\left(\mathrm{C}_{1} \mathrm{P}_{1}\right)$ papillary thyroid carcinoma. The carcinoma is in contact with the thyroid capsule and protrudes into adjacent structures in the transverse (A) and longitudinal (B) planes on sonograms from two-dimensional ultrasonography (white arrowheads). Tomographic ultrasound imaging rendered images from three-dimensional ultrasonography also demonstrate that the carcinoma is in contact with and protrudes in the transverse $(\mathrm{C})$ and longitudinal (D) planes (black arrowheads). In the coronal (E) plane, the lesion is in contact with the capsule (white arrows), but protrusion is not definite (black arrow). Final pathologic finding was negative for extrathyroidal extension.

papillary thyroid cancers are presented in Table 2 . The most commonly observed preoperative characteristics of the cancers on $2 \mathrm{D}$ US were solid (81.4\%), markedly hypoechoic (45.7\%), hypoechoic (42.9\%), irregular shape (60.0\%), ill-defined margin (87.1\%), and microcalcification with or without macrocalcification (55.7\%). The most common location was the middle third (48.6\%) of the thyroid, and, as measured by $2 \mathrm{D}$ US, the mean size for all cancers regardless of extrathyroidal extension was $0.90 \pm 0.36 \mathrm{~cm}$. The mean size of cancers with extrathyroidal extension was $0.94 \pm 0.20 \mathrm{~cm}$, which was not significantly different from the size of cancers without extrathyroidal extension $(0.89 \pm 0.40 \mathrm{~cm})$, based on the 
Table 1. Patient demographic and clinicopathological characteristics

\begin{tabular}{lc}
\hline Variable & Patient $(\mathrm{n}=61)$ \\
\hline Age, yr & $48.7 \pm 13.1(17-75)$ \\
$<45$ & $19(31.1)$ \\
$\geq 45$ & $42(68.9)$ \\
Sex & \\
Male & $5(8.2)$ \\
Female & $56(91.8)$ \\
Multifocality on histopathology & \\
\hline Thyroid carcinoma & $41(67.2)$ \\
2 Thyroid carcinomas & $14(23.0)$ \\
$\geq 3$ Thyroid carcinomas & $6(9.8)$ \\
\hline LN metastasis & $36(59.0)$ \\
Absent & $22(36.1)$ \\
\hline Central LN & $3(4.9)$ \\
\hline Central \& lateral LN & 0 \\
\hline Distant metastasis at diagnosis
\end{tabular}

Values are presented as mean $\pm \mathrm{SD}$ (range) or number (\%). LN, lymph node.

$t$ test $(p=0.483)$.

According to the histopathological reports, 55 cancers (78.6\%) were micropapillary thyroid carcinoma, and extrathyroidal extension was present in 17 (24.3\%) of the 70 carcinomas. Of these 17 cases, 15 (88.2\%) exhibited minimal extrathyroidal extension, and the other two had invaded the recurrent laryngeal nerve; 12 of the 17 cases (70.6\%) were microcarcinomas.

In terms of contact, $3 \mathrm{D}$ and $2 \mathrm{D} \mathrm{C1}$ cases were significantly associated with extrathyroidal extension $(p=0.003$ and $p=0.007$, respectively) (Table 3 ). However, in the further analysis with regard to protrusion, $2 \mathrm{D} \mathrm{Cl}_{1} \mathrm{P}$ cases in the $2 \mathrm{D} \mathrm{C}$ subgroup as well as $3 \mathrm{D} \mathrm{C} 1 \mathrm{P} 1$ cases in the 3D C1 subgroup showed no significant association $(p=$ 0.313 and $p=0.795$, respectively) (Table 4 ). Evaluation of protrusion using $3 \mathrm{D}$ US in the $2 \mathrm{D}$ C1 subgroup also did not show significant difference in the prediction of extrathyroidal extension $(p=0.772)$. For $3 \mathrm{D}$ C1 cases, the sensitivity and specificity for predicting extrathyroidal extension were $94.1 \%$ and $45.3 \%$, respectively, and for $2 \mathrm{D}$ $\mathrm{C} 1$ cases, the sensitivity and specificity were $94.1 \%$ and 41.5\%, respectively (Table 5). There were no significant differences in sensitivity and specificity between the $2 \mathrm{D}$ $\mathrm{C} 1$ and $3 \mathrm{D} \mathrm{C1}$ cases $(p=1.000$ and $p=0.754$, respectively).
Table 2. Two-dimensional ultrasonographic characteristics of papillary thyroid carcinomas

\begin{tabular}{|c|c|}
\hline Variable & Nodule $(\mathrm{n}=70)$ \\
\hline Size, cm & $0.90 \pm 0.36$ \\
\hline \multicolumn{2}{|l|}{ Location } \\
\hline Upper third & $11(15 \cdot 7)$ \\
\hline Middle third & $34(48.6)$ \\
\hline Lower third & $15(21.4)$ \\
\hline Isthmus & $10(14 \cdot 3)$ \\
\hline \multicolumn{2}{|l|}{ Degree of cystic change } \\
\hline Solid & $57(81.4)$ \\
\hline Predominantly solid & $11(15.7)$ \\
\hline Predominantly cystic & $2(2.9)$ \\
\hline \multicolumn{2}{|l|}{ Echogenicity } \\
\hline Markedly hypoechoic & $32(45 \cdot 7)$ \\
\hline Hypoechoic & $30(42.9)$ \\
\hline Isoechoic & $8(11.4)$ \\
\hline \multicolumn{2}{|l|}{ Shape } \\
\hline Ovoid to round & $19(27.1)$ \\
\hline Irregular & $42(60.0)$ \\
\hline Taller than wide & $9(12.9)$ \\
\hline \multicolumn{2}{|l|}{ Margin } \\
\hline Well defined & $9(12.9)$ \\
\hline Ill defined & $61(87.1)$ \\
\hline \multicolumn{2}{|l|}{ Calcification } \\
\hline Absent & $22(31.4)$ \\
\hline Macrocalcification & $9(12.9)$ \\
\hline Microcalcification & $39(55.7)$ \\
\hline \multicolumn{2}{|l|}{ Vascularity } \\
\hline Absent & $54(77.1)$ \\
\hline Present & $16(22.9)$ \\
\hline
\end{tabular}

Values are presented as mean $\pm \mathrm{SD}$ or number (\%).

In terms of contact, there was a discrepancy between the $3 \mathrm{D}$ and $2 \mathrm{D}$ US findings for 10 of the 70 papillary thyroid carcinomas: four cancers showed presence of contact on ${ }_{3} \mathrm{D}$ US ( $3 \mathrm{D} \mathrm{C1}$ ) but not on $2 \mathrm{D}$ US ( $2 \mathrm{D} \mathrm{Co}$ ), and six cancers showed presence of contact on $2 \mathrm{D}$ US $(2 \mathrm{D} \mathrm{C1})$ but not on $3 \mathrm{D}$ US (3D Co) (Table 6). The additional ${ }_{3} \mathrm{D}$ US assessments employed in conjunction with the standard 2D US examination for presence of contact did not significantly differ for the prediction of extrathyroidal extension in $2 \mathrm{D}$ Co and $2 \mathrm{D} \mathrm{C1}$ cases $(p=1.000$ and $p=$ ०.060, respectively). 


\section{Subgroup analyses of micropapillary thyroid carci- nomas}

The present study identified 55 micropapillary thyroid carcinomas (78.6\%) among the patients, and extrathyroidal extension was present in 12 cases (21.8\%). Similar to

Table 3. Associations between ultrasonographic presence of contact and extrathyroidal extension of papillary thyroid carcinomas

\begin{tabular}{rccc}
\hline & \multicolumn{2}{c}{$\begin{array}{c}\text { Extrathyroidal } \\
\text { extension }\end{array}$} & p value \\
\cline { 2 - 3 } Characteristic & $+(\mathrm{n}=17)$ & $-(\mathrm{n}=53)$ & \\
\hline 3D C1 $(\mathrm{n}=45)$ & 16 & 29 & $0.003^{\mathrm{a}}$ \\
$\mathrm{Co}(\mathrm{n}=25)$ & 1 & 24 & \\
2D C1 $(\mathrm{n}=47)$ & 16 & 31 & $0.007^{\mathrm{a}}$ \\
$\mathrm{Co}(\mathrm{n}=23)$ & 1 & 22 & \\
\hline
\end{tabular}

3D, three-dimentional; $\mathrm{C} 1$, presence of contact; Co, absence of contact; 2D, two-dimentional.

${ }^{\mathrm{a} C h i-s q u a r e ~ t e s t . ~}$

Table 4. Associations between coexistence of protrusion with contact and extrathyroidal extension of papillary thyroid carcinomas

\begin{tabular}{cccc}
\hline & \multicolumn{2}{c}{$\begin{array}{c}\text { Extrathyroidal } \\
\text { extension }\end{array}$} & p value \\
\cline { 2 - 3 } Characteristic & + & - & \\
\hline 3D C1 group $(\mathrm{n}=45)$ & 16 & 29 & \\
$\mathrm{C} 1 \mathrm{P} 1(\mathrm{n}=32)$ & 11 & 21 & $0.795^{\mathrm{a}}$ \\
$\mathrm{C} 1 \mathrm{Po}(\mathrm{n}=13)$ & 5 & 8 & \\
2D C1 group $(\mathrm{n}=47)$ & 16 & 31 & \\
$\mathrm{C} 1 \mathrm{P} 1(\mathrm{n}=31)$ & 9 & 22 & $0.313^{\mathrm{a}}$ \\
$\mathrm{C} 1 \mathrm{Po}(\mathrm{n}=16)$ & 7 & 9 & \\
\hline
\end{tabular}

3D, three-dimentional; $\mathrm{C} 1$, presence of contact; $\mathrm{C} 1 \mathrm{P} 1$, presence of both contact and protrusion; $\mathrm{ClPo}$, presence of contact without protrusion; 2D, two-dimentional.

${ }^{\mathrm{a} C h i-s q u a r e ~ t e s t . ~}$ the findings from the total study population, $3 \mathrm{D}$ and $2 \mathrm{D}$ $\mathrm{C} 1$ cases of micropapillary carcinoma were significantly associated with the extrathyroidal extension $(p=0.008$ and $p=0.008$, respectively; data not shown), whereas further analysis of $3 \mathrm{D} \mathrm{C} 1 \mathrm{P} 1$ cases in the $3 \mathrm{D}$ C1 subgroup and $2 \mathrm{D} \mathrm{C} \mathrm{C}_{1}$ cases in the $2 \mathrm{D} \mathrm{C}_{1}$ subgroup was not $(p=$ 1.000 and $p=1.000$, respectively; data not shown). The diagnostic characteristics of $3 \mathrm{D} \mathrm{C} \mathrm{C}_{1}$ and $2 \mathrm{D} \mathrm{C} \mathrm{C}_{1}$ were the same in this subgroup (the sensitivity was $91.7 \%$, and the specificity was $51.2 \%$ for both the $3 \mathrm{D}$ and $2 \mathrm{D}$ US; data not shown), even though there were discrepancies between the $2 \mathrm{D}$ and $3 \mathrm{D}$ US assessments in the interpretation of eight micropapillary thyroid carcinomas with respect to contact. The additional 3D US assessments following the standard $2 \mathrm{D}$ US examination for contact were not significant for either $2 \mathrm{D}$ Co or $2 \mathrm{D}$ C1 cases $(p=1.000$ and $p=0.272$; data not shown).

Table 6. Diagnostic value of additional $3 \mathrm{D}$ ultrasonography following routine $2 \mathrm{D}$ ultrasonography using contact to predict the extrathyroidal extension of papillary thyroid carcinomas

\begin{tabular}{|c|c|c|c|c|c|}
\hline \multirow{2}{*}{\multicolumn{2}{|c|}{ Characteristic }} & \multirow{2}{*}{$\begin{array}{l}\text { All nodules } \\
\qquad(\mathrm{n}=70)\end{array}$} & \multicolumn{2}{|c|}{$\begin{array}{c}\text { Extrathyroidal } \\
\text { extension }\end{array}$} & \multirow[t]{2}{*}{$p$ value } \\
\hline & & & $+(n=17)$ & $-(n=53)$ & \\
\hline $2 \mathrm{D}$ & $3 \mathrm{D}$ & & & & \\
\hline \multirow[t]{2}{*}{ Co } & Co & 19 & 1 & 18 & $1.000^{\mathrm{a}}$ \\
\hline & $\mathrm{C} 1$ & 4 & 0 & 4 & \\
\hline \multirow[t]{2}{*}{$\mathrm{C}_{1}$} & Co & 6 & o & 6 & $0.060^{b}$ \\
\hline & $\mathrm{C} 1$ & 41 & 16 & 25 & \\
\hline
\end{tabular}

3D, three-dimentional; 2D, two-dimentional; Co, absence of contact; $\mathrm{C} 1$, presence of contact.

${ }^{\mathrm{a}}$ Fisher exact test.

${ }^{\mathrm{b}}$ Chi-square test.

Table 5. Diagnostic performance of ultrasonographic presence of contact for predicting extrathyroidal extension of papillary thyroid carcinomas

\begin{tabular}{lcccccc}
\hline Characteristic & Sensitivity, \% & Specificity, \% & NPV, \% & PPV, \% & OR (95\% CI) & Az (95\% CI) \\
\hline 3D C1 & 94.1 & 45.3 & 96.0 & 35.6 & $13.241(1.635-107.209)$ & $0.697(0.569-0.825)$ \\
2D C1 & 94.1 & 41.5 & 95.7 & 34.0 & $11.355(1.400-92.066)$ & $0.678(0.547-0.809)$ \\
\hline
\end{tabular}

NPV, negative predictive value; PPV, positive predictive value; OR, odds ratio; CI, confidence interval; Az, area under the curve; 3D, three-dimentional; C1, presence of contact; 2D, two-dimentional. 


\section{DISCUSSION}

The preoperative staging of thyroid cancer is important in order in determining the extent of surgery required $[4,5]$, especially in the case of small-sized thyroid cancer. US is an essential tool during the preoperative staging of thyroid cancer to assess size, multifocality, and cervical lymph node metastasis $[4,5]$ as well as to predict extrathyroidal extension [6-9,17,18].

A number of previous studies have investigated preoperative $2 \mathrm{D}$ US characteristics that may be predictive of extrathyroidal extension of papillary thyroid cancer, and various sonographic criteria have been suggested. Kwak et al. [8] proposed contact with the capsule by $>$ $25 \%$ of the nodule perimeter could be a useful criteria for papillary microcarcinoma with sensitivity of $65.2 \%$, specificity of $81.8 \%$, and the accuracy (Az) of 0.735 . Park et al. [7] used a criteria of $>50 \%$ of the capsular abutting diameter relative to the whole tumor diameter, and reported sensitivity of $85.3 \%$, specificity of $70.0 \%$, and accuracy of $74.5 \%$. A previous study by our group evaluated 354 patients with papillary thyroid carcinomas $2 \mathrm{~cm}$ or smaller in size according to the presence of contact and the presence of protrusion into adjacent structures [9]. A multivariate analysis revealed that the presence of contact is predictive of extrathyroidal extension and that its coexistence with protrusion has an even greater predictive value. A recent study applied a more extensive criteria including either the presence of contact or the presence of protrusion, and the sensitivity, specificity, and diagnostic accuracy were $83.3 \%, 68.9 \%$, and $75.9 \%$, respectively [18].

However, those studies employed conventional $2 \mathrm{D}$ US, which has a reported false-negative rate of $14.7 \%$ to $52.0 \%[7-9,18]$. Some researchers have suggested that 3D US may provide more information regarding the relationship between thyroid cancers and the adjacent capsule in the coronal plane, and it may therefore have greater predictive value regarding extrathyroidal extension than 2D US can provide. In fact, 3D US assessment has been reported to be useful for predicting the invasion or extension of endometrial cancer [10], cervical cancer [11], prostate cancer [12], and bladder cancer [13,14] during the preoperative staging.

In assessments using $3 \mathrm{D}$ US, the volume data are scanned, stored, and later processed according to an imaging-rendering algorithm such as the multiplanar reformation mode which renders the initial $2 \mathrm{D}$ images in the longitudinal, transverse, and coronal planes simultaneously [19]. Various other imaging-rendering algorithms can be combined to acquire an optimized image [20]. TUI is a novel $3 \mathrm{D}$ post-processing technique that presents the volume data as a set of contiguous sequential slices in the transverse, longitudinal, and coronal planes in a manner similar to that of magnetic resonance or computed tomography images [20]. In a study of deep endometriosis, the TUI rendering technique was considered useful for determining the extension and depth of infiltration in the coronal plane as well as evaluating the relationship of the tumor with adjacent structures [21].

To our knowledge, only one recent study reported the diagnostic performance of ${ }_{3} \mathrm{D}$ US in the preoperative prediction of extrathyroidal extension of papillary thyroid cancer [15]. The sonographic criteria of extrathyroidal extension was either $>25 \%$ perimeter of the tumor contact with the capsule or the presence of protrusion. In the comparison with diagnostic accuracy of $2 \mathrm{D}$ US, that of $3 \mathrm{D}$ US alone was not significantly different whereas that of the combined set of $2 \mathrm{D}$ and $3 \mathrm{D}$ images was significantly higher. Sensitivity, specificity, and accuracy of combined set were $87.8 \%, 29.6 \%$, and $67.9 \%$, respectively, and those of $2 \mathrm{D}$ US were $78.2 \%, 27.2 \%$, and $60.8 \%$, respectively. Since the study included papillary thyroid carcinomas that were suspected to be in contact with the capsule on $2 \mathrm{D}$ US, the prevalence of pathologic extrathyroidal extension was as high as $65.8 \%$, which might have affected diagnostic performance. Furthermore, retrospective review of static $2 \mathrm{D}$ images could have limitation in determining the degree of contact and might partly disagree with the dynamic examination.

The present study compared the diagnostic accuracy of preoperative $2 \mathrm{D}$ and $3 \mathrm{D}$ US assessments of papillary thyroid cancers $2 \mathrm{~cm}$ or smaller in size for the prediction of extrathyroidal extension. The TUI rendering method was applied to the $3 \mathrm{D}$ volume data, and the sonographic criteria for extrathyroidal extension included the presence of contact either with or without protrusion. The 3D US assessment did not significantly differ from the 2D US assessment in terms of predicting extrathyroidal extension; the presence of contact with the thyroid capsule was significantly associated with extrathyroidal ex- 
tension on both the $2 \mathrm{D}$ and $3 \mathrm{D}$ findings. Compared with previous studies using $2 \mathrm{D}$ US, the present study had a lower false-negative rate but a higher false-positive rate for $2 \mathrm{D} \mathrm{C1}$ and $3 \mathrm{D} \mathrm{Cl}$ cases. Discrepancies between $2 \mathrm{D}$ and $3 \mathrm{D}$ US assessments concerning the interpretation of contact were found for 10 of 70 papillary thyroid carcinomas, but the additional information provided by the 3D US data did not lead to a significant difference. Although there was no statistical significance, none of the $3 \mathrm{D}$ Co cases in the $2 \mathrm{D} \mathrm{C} 1$ subgroup had extrathyroidal extension so that additional $3 \mathrm{D}$ US examination could have the possibility to be helpful to exclude extrathyroidal extension.

Even though we expected that 3 D US assessment would help to acquire more sensitive results compared with $2 \mathrm{D}$ US examination by providing additional information in the coronal plane, $3 \mathrm{D}$ C1 showed a tendency to be more specific rather than sensitive in predicting extrathyroidal extension compared with $2 \mathrm{D} \mathrm{C1}$. One possible reason is that images in the coronal plane of $3 \mathrm{D}$ US have relatively poor resolution, and are not as familiar to the examiner as with $2 \mathrm{D}$ images. The coronal plane of $3 \mathrm{D}$ US is a virtual reconstruction completed by the computer. Consequently, images in the coronal plane have relatively poor resolution, which sometimes obscure and complicate evaluation in the coronal plane $[19,22]$. Another possible reason is that the $2 \mathrm{D}$ US data were assessed in real time and interpreted immediately, whereas the $3 \mathrm{D}$ data were stored before being rendered and then retrospectively assessed. This difference in the timing of assessment reflects real conditions in the clinical field. Compared with retrospective analysis of stored $2 \mathrm{D}$ data, real time assessment could be more variable according to the observers and cannot be re-evaluated afterwards. On the other hand, US examiners can make decision on the basis of dynamic assessment of spatial relationship so that real time interpretation could be more preferred especially when the degree of contact should be determined as in some cases of the previous studies using $2 \mathrm{D}$ US.

Unlike our previous study, the concomitant presence of protrusion in addition to contact was not significantly associated with extrathyroidal extension in either the $2 \mathrm{D}$ or the $3 \mathrm{D}$ US data. Further analysis of the presence of protrusion on $3 \mathrm{D}$ US in the $2 \mathrm{D} \mathrm{C}$ subgroup did not show significant association as well. Much lower preva- lence of extrathyroidal extension and different examiners from the previous study might be the cause of dissimilarity.

The present study has several limitations. First, the prevalence of extrathyroidal extension was relatively low considering that the rate of extrathyroidal extension observed in previous studies was $36.2 \%$ to $55.1 \%[6-9,17,18]$. Although the present study included papillary thyroid carcinomas larger than $1 \mathrm{~cm}$, extrathyroidal extension was reported in only 17 of 70 papillary thyroid carcinomas (24.3\%), and just two of these grossly invaded the recurrent laryngeal nerve. This may reflect a recent trend toward the increased detection of early-stage thyroid cancer. Second, our study subjects had higher proportion of female. The male to female ratio in the incidence of thyroid cancer has been reported about 1:3.5 to 1:5 $[3,23,24]$. Men are probably related to more advanced disease at presentation: larger primary tumor size, higher rates of extrathyroidal extension, regional lymph node metastasis, and distant metastasis in all age groups [24]. In our study, only five male patients with six thyroid carcinomas were included and the male to female ratio was as small as 1:11.2. None of these male patients had extrathyroidal extension, which might be a contributing factor to a lower prevalence of extrathyroidal extension in our study group. Third, contact was categorized in terms of presence or absence. In a previous study using conventional 2D US, the criteria for contact alone had higher sensitivity but lower specificity and diagnostic accuracy for predicting extrathyroidal extension compared with criteria that required more than $25 \%$ contact [8]. Categorization based on the degree of contact should be further evaluated in the future study using $3 \mathrm{D}$ US. Fourth, the present study used only the TUI method to analyze the relationship between the thyroid cancer and the adjacent capsule. For better visualization of the images in the coronal plane, the concomitant use of other post-processing algorithms may be needed. A thin-slice smooth-surface rendering algorithm was found to provide a more detailed visualization of thyroid nodules such that twice the number of thyroid nodules in the coronal plane could be analyzed using this technique compared with the multiplanar reformation mode $[20,22]$. The volume contrast imaging method also has been reported to enhance the tissue demarcation of endometrial cancer $[10]$ and could be a useful method for 
the assessment of thyroid cancer as well [20]. Fifth, we did not evaluate the interobserver or intraobserver variability in interpreting the presence of contact and protrusion on $2 \mathrm{D}$ and $3 \mathrm{D}$ US. To our knowledge, two studies have evaluated interobserver agreement of US for the assessment of extrathyroidal extension of thyroid cancer, and fair to moderate agreement with $2 \mathrm{D}$ US $[25,15]$ and moderate agreement with $3 \mathrm{D}$ US [15] were reported. Relatively inferior interobserver agreement may be partly because the criteria for assessing extrathyroidal extension has not been clearly established in comparison with other criteria such as that for defining metastatic lymph node [25]. In addition, since our study assessed with $2 \mathrm{D}$ US in real time manner whereas with $3 \mathrm{D}$ US in retrospective review, interpretations could have been even more variable. Sixth, we included papillary thyroid carcinomas $2 \mathrm{~cm}$ or smaller size so that the diagnostic value of $3 \mathrm{D}$ US in comparison with $2 \mathrm{D}$ US for larger size cancers could not be determined in the present study.

In conclusion, 3D US data rendered with the TUI algorithm alone and then analyzed based on the presence or absence of contact do not seem to have remarkable advantage over evaluation with real-time $2 \mathrm{D}$ US for the prediction of the extrathyroidal extension of papillary thyroid carcinoma. However, in the cases with presence of contact on $2 \mathrm{D}$ US, further assessment with $3 \mathrm{D}$ US could be marginally helpful to exclude extrathyroidal extension. A combination of other reconstruction algorithms of $3 \mathrm{D}$ volume data and categorization based on the degree of contact should be further evaluated in the future.

\section{KEY MESSAGE}

1. Three-dimensional ultrasonography data rendered with the tomographic ultrasound imaging do not seem to have remarkable advantage over evaluation with real-time two-dimensional ultrasonography in predicting the extrathyroidal extension of papillary thyroid cancer.

2. A combination of other reconstruction algorithms of three-dimensional ultrasonography data and categorization based on degree of contact should be further evaluated in the future.

\section{Conflict of interest}

No potential conflict of interest relevant to this article was reported.

\section{Acknowledgments}

This study was supported by Biomedical Research Institute Grant (2012-01), Pusan National University Hospital.

\section{REFERENCES}

1. Davies L, Welch HG. Increasing incidence of thyroid cancer in the United States, 1973-2002. JAMA 2006;295:21642167.

2. Chen AY, Jemal A, Ward EM. Increasing incidence of differentiated thyroid cancer in the United States, 1988-2005. Cancer 2009;115:3801-3807.

3. Cho BY, Choi HS, Park YJ, et al. Changes in the clinicopathological characteristics and outcomes of thyroid cancer in Korea over the past four decades. Thyroid 2013;23:797-804.

4. American Thyroid Association (ATA) Guidelines Taskforce on Thyroid Nodules and Differentiated Thyroid Cancer, Cooper DS, Doherty GM, et al. Revised American Thyroid Association management guidelines for patients with thyroid nodules and differentiated thyroid cancer. Thyroid 2009;19:1167-1214.

5. Yi KH, Park YJ, Koong SS, et al. Revised Korean Thyroid Association management guidelines for patients with thyroid nodules and thyroid cancer. Endocrinol Metab 2010;25:270-297.

6. Jeong HS, Chung M, Baek CH, Ko YH, Choi JY, Son YI. Can [18F]-fluorodeoxyglucose standardized uptake values of PET imaging predict pathologic extrathyroid invasion of thyroid papillary microcarcinomas? Laryngoscope 2006;116:2133-2137.

7. Park JS, Son KR, Na DG, Kim E, Kim S. Performance of preoperative sonographic staging of papillary thyroid carcinoma based on the sixth edition of the AJCC/ UICC TNM classification system. AJR Am J Roentgenol 2009;192:66-72.

8. Kwak JY, Kim EK, Youk JH, et al. Extrathyroid extension of well-differentiated papillary thyroid microcarcinoma on US. Thyroid 2008;18:609-614.

9. Kim SS, Lee BJ, Lee JC, et al. Preoperative ultrasono- 
graphic tumor characteristics as a predictive factor of tumor stage in papillary thyroid carcinoma. Head Neck 2011;33:1719-1726.

10. Jantarasaengaram S, Praditphol N, Tansathit T, Vipupinyo C, Vairojanavong K. Three-dimensional ultrasound with volume contrast imaging for preoperative assessment of myometrial invasion and cervical involvement in women with endometrial cancer. Ultrasound Obstet Gynecol 2014;43:569-574.

11. Byun JM, Kim YN, Jeong DH, Kim KT, Sung MS, Lee KB. Three-dimensional transvaginal ultrasonography for locally advanced cervical cancer. Int J Gynecol Cancer 2013;23:1459-1464.

12. Mitterberger M, Pinggera GM, Pallwein L, et al. The value of three-dimensional transrectal ultrasonography in staging prostate cancer. BJU Int 2007;100:47-50.

13. Park HJ, Hong SS, Kim JH, et al. Tumor detection and serosal invasion of bladder cancer: role of three-dimensional volumetric reconstructed US. Abdom Imaging 2010;35:265-270.

14. Li QY, Tang J, He EH, et al. Clinical utility of three-dimensional contrast-enhanced ultrasound in the differentiation between noninvasive and invasive neoplasms of urinary bladder. Eur J Radiol 2012;81:2936-2942.

15. Gweon HM, Son EJ, Youk JH, Kim JA, Park CS. Preoperative assessment of extrathyroidal extension of papillary thyroid carcinoma: comparison of 2- and 3-dimensional sonography. J Ultrasound Med 2014;33:819-825.

16. Hawass NE. Comparing the sensitivities and specificities of two diagnostic procedures performed on the same group of patients. Br J Radiol 1997;70:360-366.

17. Choi JS, Chung WY, Kwak JY, Moon HJ, Kim MJ, Kim
EK. Staging of papillary thyroid carcinoma with ultrasonography: performance in a large series. Ann Surg Oncol 2011;18:3572-3578.

18. Lee CY, Kim SJ, Ko KR, Chung KW, Lee JH. Predictive factors for extrathyroidal extension of papillary thyroid carcinoma based on preoperative sonography. J Ultrasound Med 2014;33:231-238.

19. Fernandez LJ, Aguilar A, Pardi S. Three-dimensional ultrasound in small parts: is it just a nice picture? Ultrasound Q 2004;20:119-125.

20. Slapa RZ, Jakubowski WS, Slowinska-Srzednicka J, Szopinski KT. Advantages and disadvantages of ${ }_{3} \mathrm{D}$ ultrasound of thyroid nodules including thin slice volume rendering. Thyroid Res 2011;4:1.

21. Guerriero S, Alcazar JL, Ajossa S, Pilloni M, Melis GB. Three-dimensional sonographic characteristics of deep endometriosis. J Ultrasound Med 2009;28:1061-1066.

22. Slapa RZ, Slowinska-Srzednicka J, Szopinski KT, Jakubowski W. Gray-scale three-dimensional sonography of thyroid nodules: feasibility of the method and preliminary studies. Eur Radiol 2006;16:428-436.

23. Jung KW, Won YJ, Kong HJ, Oh CM, Lee DH, Lee JS. Cancer statistics in Korea: incidence, mortality, survival, and prevalence in 2011. Cancer Res Treat 2014;46:109-123.

24. Nilubol N, Zhang L, Kebebew E. Multivariate analysis of the relationship between male sex, disease-specific survival, and features of tumor aggressiveness in thyroid cancer of follicular cell origin. Thyroid 2013;23:695-702.

25. Moon HJ, Yoon JH, Kwak JY, et al. Positive predictive value and interobserver variability of preoperative staging sonography for thyroid carcinoma. AJR Am J Roentgenol 2011;197:W324-W330. 